\title{
Seizure Disorder
}

National Cancer Institute

\section{Source}

National Cancer Institute. Seizure Disorder. NCI Thesaurus. Code C3020.

A brain disorder characterized by episodes of abnormally increased neuronal discharge resulting in transient episodes of sensory or motor neurological dysfunction, or psychic dysfunction. These episodes may or may not be associated with loss of consciousness or convulsions. 